\title{
Cloud Based Public Collaboration System in Developing Countries
}

\author{
Sherif M. Badr \\ Chairman of Information and Decision Support Center \\ The Egyptian Cabinet \\ Cairo, Egypt.
}

\author{
Sherif E. Hussein \\ Computer and Systems Department \\ Mansoura University \\ Mansoura, Egypt.
}

\begin{abstract}
Governments in developing countries are increasingly making efforts to provide more access to information and services for citizens, businesses, and civil servants through smart devices. However, providing strategically high impact $\mathbf{m}$-services is facing numerous challenges, such as complexity of different mobile technologies, creating secured networks to deliver reliable service, and identifying the types of services that can be easily provided on mobile devices. Those problems could be solved by applying cloud computing model to the business process of E-government to build a government cloud. This research, proposes an environment for citizens to have greater access to their government and, in theory, makes citizen-to-government contact more inclusive. In addition, it examines an application that allows anyone to report and track non-emergency issues via the internet. It can also encourage citizens to become active in improving and taking care of their community by reporting issues in their neighborhood in order to improve the Egyptian e-government development index.
\end{abstract}

\section{Keywords-e-government; m-government; cloud computing}

\section{INTRODUCTION}

The emergence of new information and communication technologies has not only revolutionized the way business is conducted but also transformed the delivery mechanism of governmental services. Since the 1990s, public-sector organizations across the globe have been applying internet technology and other computing technologies in innovative ways to deliver services, engage citizens, and improve efficiency using a set of practices commonly known as electronic government (e-government) [1] .

E-Government is rapidly becoming one of the government's critical means for the provision of seamless services for public agencies, businesses, and citizens [2,3]. It is the use of information and communication technologies as a tool to achieve better government. Its innovation and development can position the public sector as a driver of demand for Information and Communication Technology (ICT) infrastructure and applications in the broader economy [4]. Moreover, an explosion in the use of mobile technologies, such as smart phones, laptops, and tablets to connect to wireless networks has enabled governments to change from e-government to $\mathrm{m}$ government. M-Government is an emerging trend in government services and applications delivery [5].
It creates and guarantees mobility and portability for the public, business, and government. Furthermore, real-time access to information and personalization of information access are guaranteed to maximize benefits of using information and, in turn, create further advanced e-Government services [6, 7]. However, providing strategic impact, and secured m-services, dealing with the complexity of different mobile technologies, and creating secure networks to realize reliable services are the major challenges for government institutions [8].

The potential for $\mathrm{m}$-Government in developing countries, however, remains largely unexploited, even though, governments in developing countries are increasingly making efforts to expand mobile networks infrastructure to provide more access to information and services for citizens through wireless devices [9, 10]. While e-Government encompasses usage of all technologies to deliver services to citizens and improve the activities of government and streamline their processes, m-government presents an expansion to the eGovernment to use mobile technologies in delivering services.

In addition, $\mathrm{m}$ - Government is a better option compared to e-Government in delivering services and public information to citizens due to its nature of being available anywhere, anytime and from any internet enabled device. The trend towards $\mathrm{m}$ Government has been facilitated by growing capabilities of mobile technologies and their associated infrastructures, devices and systems and their acceptance in both developed and developing countries [11].

M-Government can be applied to four main purposes such as $\mathrm{m}$-services, $\mathrm{m}$-communications, $\mathrm{m}$-administration, and $\mathrm{m}$ democracy in the public sector. Like e-Government, mGovernment operates on four different levels of interactions as identified in figure 1.

Figure 1 describes the four levels of interactions which are m-government-to-citizen (mG2C), that refers to the interaction between government and citizens; $\square$ m-government-to-business $(\mathrm{mG} 2 \mathrm{~B})$, describing the interaction between government and businesses; m-government-to-employee (mG2E), also known as internal effectiveness and efficiency (IEE), is concerning the government and its employees; and m-government-togovernment $(\mathrm{mG} 2 \mathrm{G})$, referring to inter-agency relationships and the interactions between government agencies [12]. 


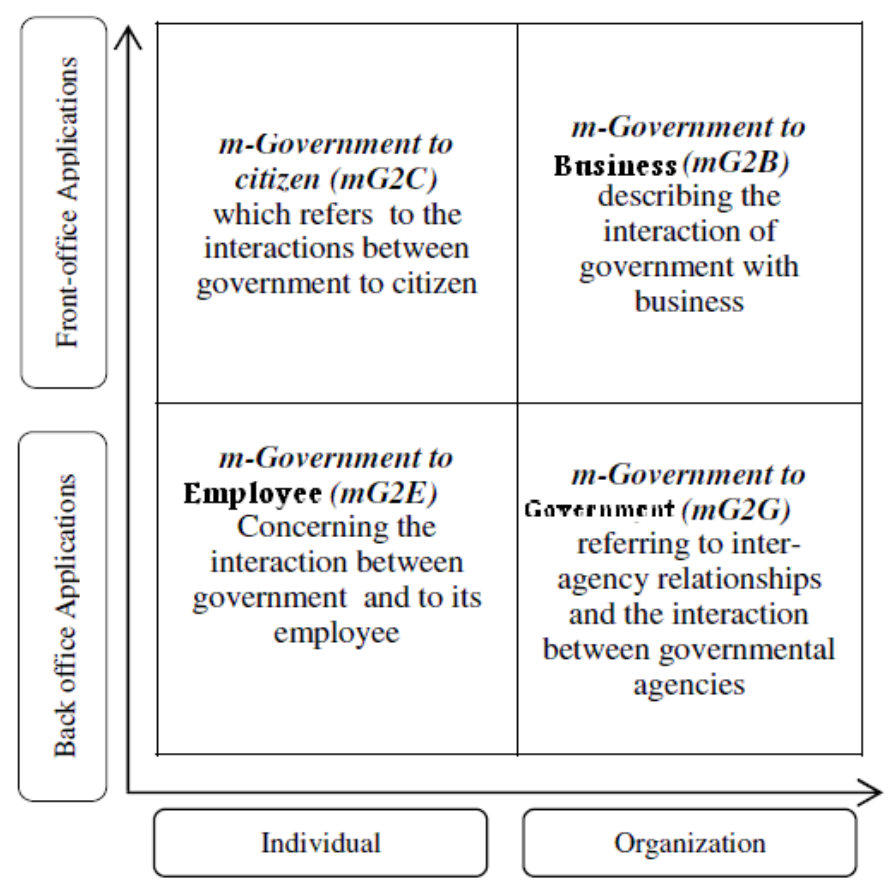

Fig. 1. $\square$ The four levels of interactions are m-government-to-citizen (mG2C), m-government-to-business (mG2B), m-government-to-employee (mG2E), and m-government-to-government (mG2G).

There are several attractive features that prompt shift toward m-Government in developing countries [13]:

- Number of mobile users and increasing penetration: More people than ever have ownership of mobile devices capable of accessing e-services and e-contents.

- Mobiles connecting people to the Internet: Urban users are using mobiles to receive an "Internet experience" through Wireless Application Protocol (WAP) services provided over General packet radio service (GPRS).

- Mobility: Enables people to access content wherever they are.

- Inclusiveness and Remote area access: Mobile phones, can reach those areas where the infrastructure necessary for Internet services or wired phone services is difficult to setup. In the developing countries mobile government applications may become a key method for reaching citizens in far and wide areas and promoting exchange of communications. In such countries with insufficient conventional telecom infrastructures and greater acceptance of mobile phones, the ability of reaching rural areas may be considered as an important feature of m-Government. Mobile technologies increase inclusion of the most marginalized people in society.

- Low Cost: Mobile phone is relatively a low cost technology, which the common person can afford to have it as compared to internet technology.

- Ease of Learning: Usage of mobile devices is fairly simple, making it easy for any person to use and to access information.
- Easy Infrastructure Setup: Due to the simple architecture of mobile telephony, new mobile phone networks can be easily installed in countries where infrastructure complexity and cost are not feasible.

- Improvement on e-Government effort: M-government is not a replacement to e-Government but complementary to it. Also, it helps in expanding the scope of e-Governance in areas like e-Democracy, eParticipation, e-Voting and many other forms of communication between the citizen and the government.

The application designed and evaluated here is a Public Collaboration System (PCS). It is a collaboration between citizen and government. The proposed application aims to use wireless/mobile technologies to provide information and services for citizens $(\mathrm{mG} 2 \mathrm{C})$. PCS allows anyone to report and track non-emergency issues via the internet as well as encouraging citizens to become active in improving and taking care of their community by reporting issues in their neighborhood. There are already a lot of involved citizens and hard-working local authorities and service people. The proposed application seeks to use the potentials of the internet and mobile computing to bring them closer together and reach even more people.

\section{Methodology}

To achieve citizen approval and extensive use of $\mathrm{m}$ government services, the selection of both technology and services should match the actual requests of people.

Consequently, limitations and strong points inherent to the use of mobile and wireless technologies for public service provision should be considered through the prism of user centricity.

The crucial aim of introducing government services via new technological means is to create an added value. Undeniably, the added value of m-government is mobility itself. Nevertheless, the value given by mobility comes, not from the accessibility of certain services through mobile phones, but from capability of these services to support mobility of the user. Different aspects of mobility and its inferences to government environment are vital for appreciating the individuality of $\mathrm{m}$-government concept, as well as obstacles and motivations to m-government service adoption [14].

The same technological features of a mobile device (small screen, miniaturized keyboard, etc.) constraining the application of enhanced services to mobile environment, on the other hand, constitute additional value for the user, as they increase the mobility level of the device.

The United Nations Public Administration Programme (UNPAP) has developed a number of indices to measure the egovernment performance. Those measures are updated annually since its creation in 2003. It covers all Member states of the UN. Among those measures is the E-Government Readiness Index (EGDI) which is a composite measure of the capacity and willingness of countries to use e-government for ICT-led development countries to use e-government for ICT- 
led development. The EGDI looks at the most important dimensions of e-government: (i) scope and quality of online services, (ii) telecommunication connectivity, and (iii) human capacity [15].

Governments' efforts are ranked, while countries size, infrastructure availability and ICT penetration, and the level of education and skill development are taken into account. Closely connected to the survey, the UNPAP also produces an E-Participation Index. The index rates the performance of national governments relative to one another by averaging three other indices: the Online Service Index, the Telecommunication Index and the Human Capital Index. The maximum possible value is one and the minimum is zero. Though the basic model has remained constant, the precise meaning of these values varies from one survey to the next as understanding of the potential of e-government changes and the underlying technology evolves.

The United Nations Survey 2012 assessment of progress indicates that e-government is increasingly being viewed among countries in the vanguard as going beyond service delivery towards a framework for a smart, inclusive and sustainable growth for future generations. In countries that follow that trend, a focus on institutional integration coupled with online citizen orientation in public service continues to be dominant. Both in terms of information and services, the citizen is increasingly viewed as 'an active customer of public services' with borrowed private sector concepts being applied to improve public sector governance systems. A key driver for this approach is the need to achieve efficiency in government at the same time that services are being expanded. Advances in technology, which allow data sharing and efficient streamlining of cross-agency governance systems are forming the back-end of integrated portals where citizens find a myriad of relevant information arranged by theme, life cycle or other preferred use. The trend towards personalization of services has gained momentum with more countries tailoring substance and presentation in accord with varied preferences. Multichannel service delivery features were found on several portals in 2012 through which the government conducted business with citizens. Citizen inclusion is also expanding both horizontally and vertically with more governments around the world in 2012 accepting and promoting the need to inform and involve - the citizen in the public decision making process [16].

E-government innovation and development can position the public sector as a driver of demand for ICT infrastructure and applications in the broader economy. The effect will be more pronounced in cases where government programmes constitute a significant proportion of a country's GDP and where the regulatory environment is conducive to expansion of ICT manufacturing, software and related services. E-government programmes can be a catalyst in boosting productivity, thereby speeding up the benefits of newer technologies to the people. In the last few years many countries have employed ICT in areas such as entrepreneurship, innovation, research and development, promoting distance learning, e-health, eagriculture, e-trade and other fields. Accessing these new technologies for development is being recognized as one of the key sources of economic growth. Of particular importance is the effect of cellular technologies. Where national governments have taken a lead, rapid mobile technology proliferation has contributed as much as a one percent annual increase in economic growth over the last few years. Not with standing these trends, progress remains uneven. In the current recessionary climate some countries have been better able to continue to invest in ICT infrastructure and service improvement. Others are evaluating the marginal utility of such investment, especially taking into account low user uptake of existing services, and reassessing service portfolios where demand for online services is low. Many countries with low levels of infrastructure and human capital remain at lower levels of e-government development with serious issues of digital divide [17].

In all cases, e-government take a prominent role in shaping development making it more in tune with people's needs and driving the whole process based on their participation.

Africa has seen improvement in e-government with countries in the region looking to increase their online presence through developing websites for government ministries and agencies. Table 1 shows that Seychelles (0.5192) climbed several points to number one in the region in 2012 followed by Mauritius (0.5066) and South Africa (0.4869).

TABLE I. E-GOVERNMENT TOP RANKED COUNTRIES IN AFRICA

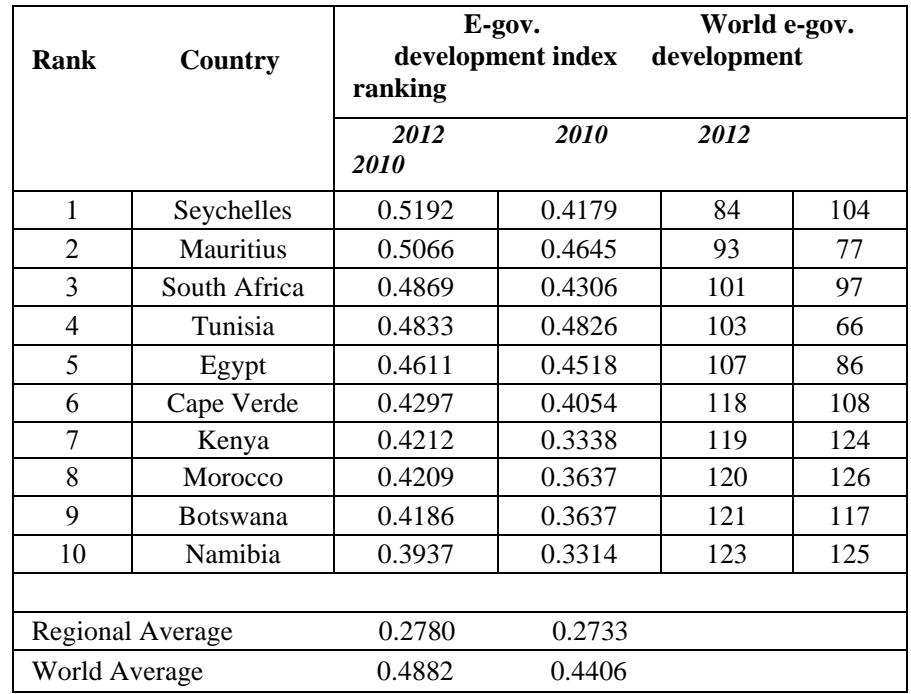

It is notable that all of the leading African countries increased their e-government development index value in 2012 but lost in comparative performance around the world, except for Seychelles, Kenya and Morocco, which gained in the world rankings from 104 to 84,124 to 119 and from 126 to 120 respectively. Tunisia (0.4833) and Egypt (0.4611) declined in rank substantially as did Cape Verde (0.4297) because their improvements did not keep pace with those of other countries around the world [15].

An example of a big improvement in EGDI was in Kazakhstan. Kazakhstan has improved from 2010 in terms of providing online features that allows citizens to engage with government. An interesting online participation feature is the government's Blogs site, where citizens can communicate with the government agencies' executives by posting comments and 
questions. The executives may then respond and post their answers on the blog. The site also contains statistical information on the questions and comments an agency executive has received as well as how many times he/she has responded. Another example was Bahrain. Bahrain's egovernment strategy is based upon "delivering customer value through collaborative government." The government sees citizens as customers who have different needs and demand different services and at the same time demand value for money. Thus the aim of e-government is to provide all services, integrated, to all citizens and upon their choice of channel. The Kingdom provides delivery of services through the following channels: e-government portal, mobile portal, national contact centre (a 24-7 call centre) and e-services centers and kiosks. Bahrain has introduced the "Listen" feature, which enables people with visual disabilities to hear any text available on the website with the click of a button. Another very innovative feature is the e-government toolbar, which can be downloaded permanently to your browser. This allows direct access to e-services and RSS feeds without having to go to the main portal [18].

Though, there is considerable progress in the expansion of online services, one of the primary challenges that remain in Least Developed Countries (LDC's) is integration of back-end processes with efficient, user friendly, and target oriented services delivery. The proposed application tackles those limitations using a back-end deployed over the cloud. That kind of deployment takes advantage of both unlimited scalability and minimum cost as will be explained in the implementation section.

Moving from improving public sector efficiency, Europe looks to take this role further in adapting innovative technologies to human development and economic sustainability in the future.

E-government innovation and development can position the public sector as a driver of demand for ICT infrastructure and applications in the broader economy. For e-participation to contribute to sustainable development and the socio-economic uplift of the people, the role of government requires a shift from that of a controller of information and services to that of a proactive facilitator. In this context, it is imperative that information and services are geared toward promoting user uptake, addressing the needs and concerns of the citizenry, especially the vulnerable. It also requires viewing the citizens not only as passive receivers of information through web based services, but also as active partners who are engaged and supported to interact with the government through ICT-based dissemination of relevant government information. The best performing countries in e-participation appear in table 2. Once again the Republic of Korea tops the list, but this year it is joined by the Netherlands. Kazakhstan (0.9474), a developing country, which was noted in the 2010 Survey for its commitment to e-participation, moved up 16 places to be ranked second and tied with Singapore. Among this group several other countries were tied for the same spot, such as Australia, Estonia, and Germany, which were all at the 5th position. With the use of consultation tools, including social media, other developing countries have also caught up to the developed countries as e-leaders. Notable among these are
Bahrain, Egypt, the United Arab Emirates, Colombia, and Chile. Europe's share of the top ten fell from 51 per cent in 2010 to 38 percent this year. This change was primarily the result of the Americas increasing from 14 per cent to 19 per cent with Chile and Colombia joining the leaders, along with the appearance of Egypt from Africa, and Bahrain and the United Arab Emirates from Western Asia [15].

TABLE II. WORLD E-PARTICIPATION RANKING

\begin{tabular}{|c|c|c|}
\hline E-participation index & Country & \multirow{2}{*}{ Rank } \\
\hline 1.0000 & Netherlands & \multirow{2}{*}{1} \\
\hline 1.0000 & Republic of Korea & \multirow{2}{*}{2} \\
\hline 0.9474 & Kazakhstan & \multirow{2}{*}{3} \\
\hline 0.9474 & Singapore & \multirow{2}{*}{4} \\
\hline 0.9211 & United Kingdom & \multirow{2}{*}{5} \\
\hline 0.9211 & United States & \multirow{2}{*}{6} \\
\hline 0.8947 & Israel & \multirow{2}{*}{6} \\
\hline 0.7632 & Australia & \multirow{2}{*}{7} \\
\hline 0.7632 & Estonia & \\
\hline 0.7632 & Germany & \\
\hline 0.7368 & Columbia & \\
\hline 0.7368 & Finland & \multirow{2}{*}{8} \\
\hline 0.7368 & Japan & \\
\hline 0.7368 & United Arab Emirates & \\
\hline 0.6842 & Egypt & \\
\hline 0.6842 & Canada & \\
\hline 0.6842 & Norway & \\
\hline 0.6842 & Sweden & \\
\hline 0.6579 & Chile & \multirow{2}{*}{} \\
\hline 0.6579 & Bahrain & \\
\hline 0.6579 & Russian Federation & \\
\hline
\end{tabular}

Table 2 shows the potentials for some countries to improve their EDGI. Governments with high e-participation values and low EDGI need to re-evaluate their e-government policies and to take advantage of the willingness of their citizens to be an active part in the government decision making.

\section{SYSTEM ANALYSIS}

As an attempt to increase the world e-government development ranking in developing countries, a system has been designed to take advantage of the already existing mobile users that are willing to participate in the government policy making and take advantages of any available mobile services. The proposed system deals with many government factions and departments that offer public services. It allows users to report different problems they can find (road hazard, crowd, environmental pollution or risk, unlawful use of public resources, etc.) and vote for published ones and at the same time trace the government procedures to solve them. The system had to include a validation module to screen, classify and group problems to be easily administered. It had to use as well an expert system module to support both users and government departments for the best procedure for a particular problem. The expert system knowledgebase increases as the system serves more users. Another important feature for the system is the ability to load balance user requests when number of users increase. That feature uses a platform as a Service (PaaS) which can allocate resources unlimitedly with proper security measures. The platform is typically represented as a single box [19]. Since the platform usually acts as if it were a single box, it's much easier to work with, and generally there is no need to change much in the application to be able to run on 
a PaaS environment. PaaS doesn't only offer CPU, memory or file storage; but also offers other parts of the infrastructure, such as databases, either in the form of a scaling traditional RDBMS system, or one of the 'NoSQL' databases [20, 21].

Figure 2 describes the features the moment citizens start to participate in the system. At first the user from the client side usually a mobile device or a desktop takes a picture of the problem he sees, adds notations, and sends it through the web to inform the authorities about it. He can also review other problems that have been published before. As an added feature to the system, is the ability of the user, if he is in a place without internet coverage, to automatically save the problem in the internal database of the client. When internet connection becomes available, the system sends the saved problems upon user request. After the problem is sent, a copy is saved in the back-end database to be opened and filtered by a validation module to check for its consistency before to be saved in the database published on the website. The government reviews the approved problems and sends their progress to the web server.

The user can review other problems using his dashboard from a mobile or a desktop through a website URL or can search for certain problems or just check the most recent problems and vote for them.

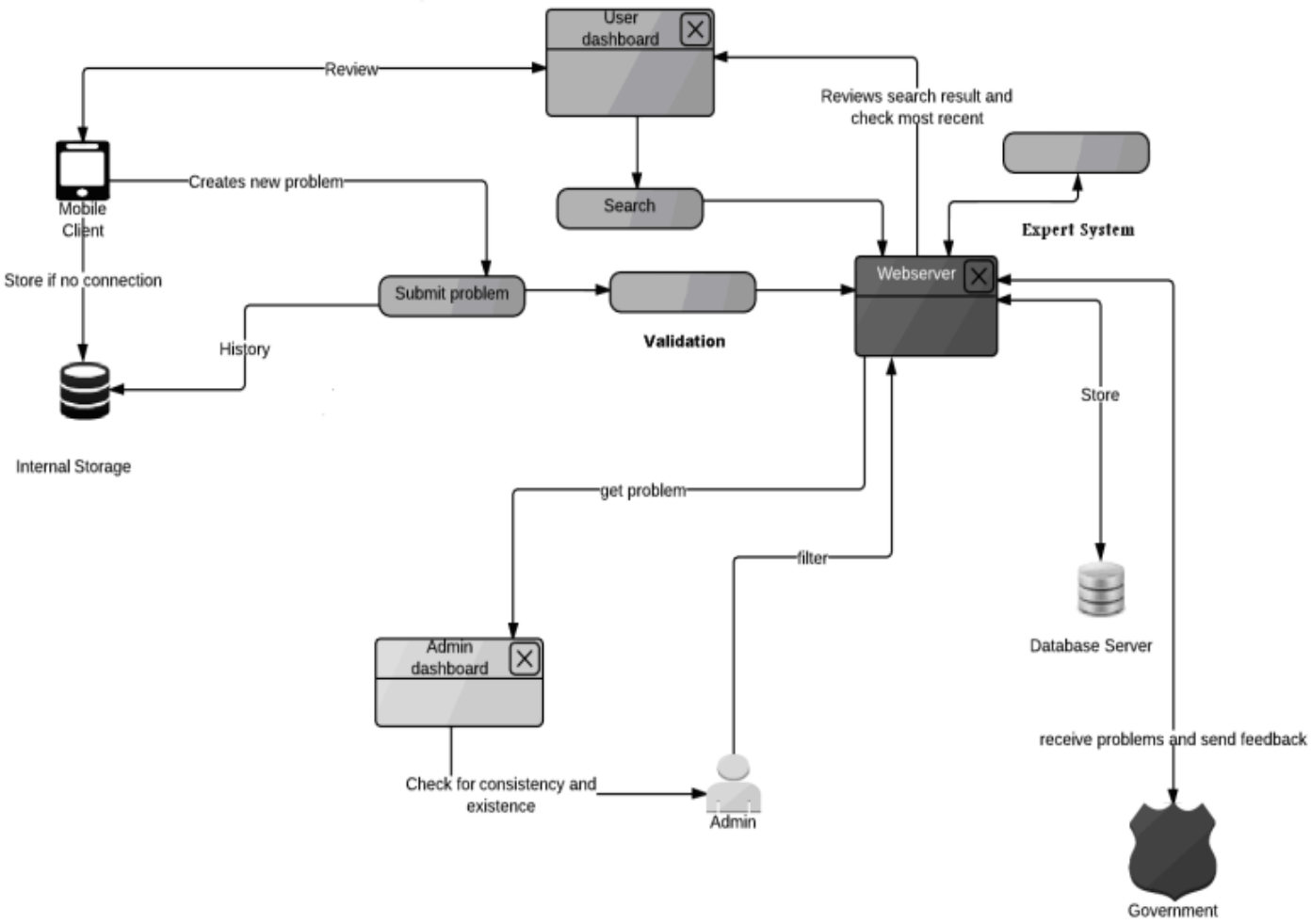

Fig. 2. PCS life cycle diagram 


\section{A. Sequence diagram}

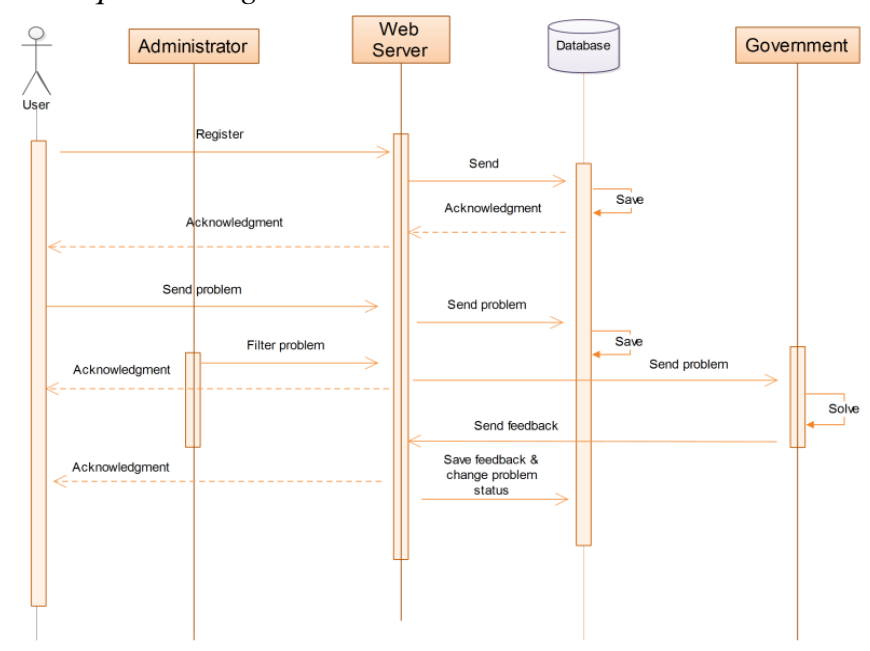

Fig. 3. PCS sequence diagram

The sequence diagram shown in figure 3 describes objects interactions arranged in time sequence. It depicts the objects involved in the scenario and the sequence of actions exchanged between the objects needed to carry out its functionality. If the user is not a registered member, the system allows him to register before the problem data is sent to the web server. The validation module then checks the consistency and validity of the problem sent. If the problem is inconsistent with the registration regulation the user is suspended after administrative review and no further action will be taken to process the problem by the government. Filtered problems will be published and an acknowledged will be sent to the user. The government will review the problems and change its status according to the progress it has achieved. The user can see his problem progress or other published problems through the front-end.

\section{B. Context diagram}

The Context Diagram shown in figure 4 describes the scope of the system which consists of two entities (citizen and government), the citizen can register and send a problem to the system, then receive acknowledgement of the process status. Government receives the problem details from the system then provides the system with a feedback for the problem progress. There are few levels that depict the context diagrams which are summarized as follows:

Level 0: In this level, the system is decomposed into frontend (mobile application or web application) and web server system, citizen can register through the web or the mobile then receives an acknowledgement by the process status.

Level 1: In this level, the front-end is decomposed into three processes. The first process checks whether the user is registered or not, and if he is already registered, it sends user data to the database server. In the second process, the problem system receives problem data including (image, description, location, and category) and responds by an acknowledgement to notify users by the process status. In case the citizen has no internet connection, the problem data will be saved into an internal database until connection is available, and then will be sent to the web server.

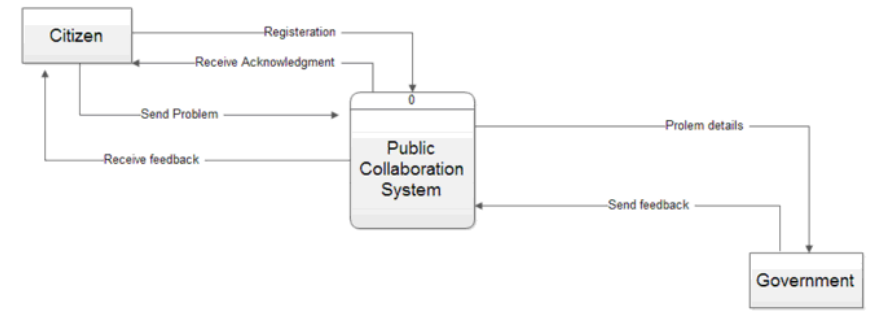

Fig. 4. PCS context diagram

Level 2: In this level, the system is decomposed into three processes. Receive and send data, manage reports, check the registration status. The first module receive problem that and send it to the database server. The manage report change data status according to a validation filtration and the government solution progress. The registration module can register a new user or check whether he is a registered member or not.

Level 3: In this level, manage report is decomposed into three processes; filter report, publish report, and feedback system. The problem is sent to be filtered by a validation module then detects if the problem exists and whether it is consistent, then sends it to the publish report. If it is really a problem, then it sends it to the government. If not, it discards it before notifying the user with its status and changes the user status to be suspended.

\section{The validation module}

As more and more users use the service, overload could occur (too many submissions, duplicate submissions-same problem). Thus, for administrators and government not to waste too much time and effort organizing and collating submissions, a validation module is needed. It can organize submissions: group similar problems (and create statistical data) according to keywords in submission (text), pattern recognition (image), and statistics based on location, time, etc. The module can assign higher priority to problems from trusted users (users with previous popular submission according to public votes). It can also increase the priority of problems according to votes or number of occurrence.

\section{The expert system module}

An expert system gives advices to guide citizens and government the best procedure to solve a problem according to previous solutions stored in the expert system's knowledgebase. The expert system can serve as well to group problems data and help users categorizing their problems. ES can continuously learns new solutions as they are solved by the government and tracks unsolved problems reasons and suggests solutions.

\section{System Design}

In the proposed system, the architecture was separated into software and service architecture:

Software architecture: The set of structures needed to reason about the software system, which comprises the software elements, the relations between them, and the properties of both elements and relations. Figure 5 shows the PCS mobile interface with its different application components, 
It needs to have consistent look irrespective to which smart phone is using the PCS application.

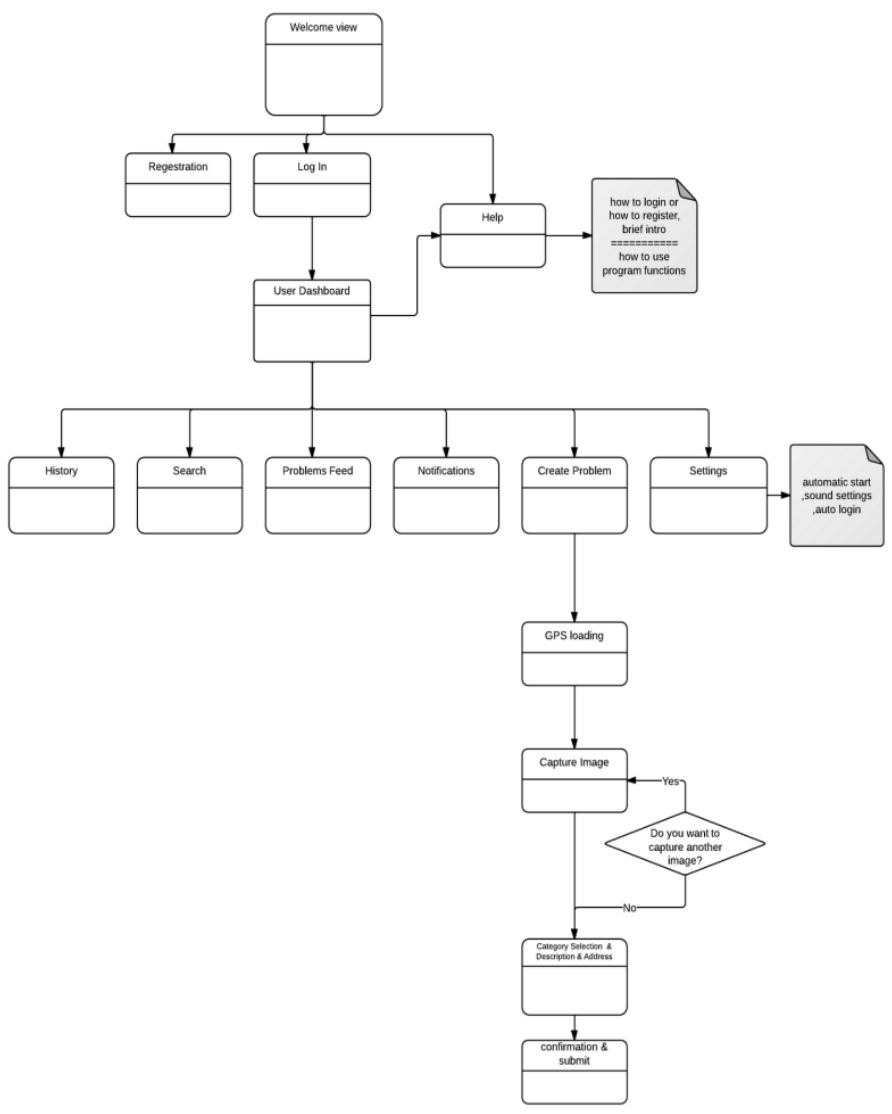

Fig. 5. The PCS mobile front-end structure chart

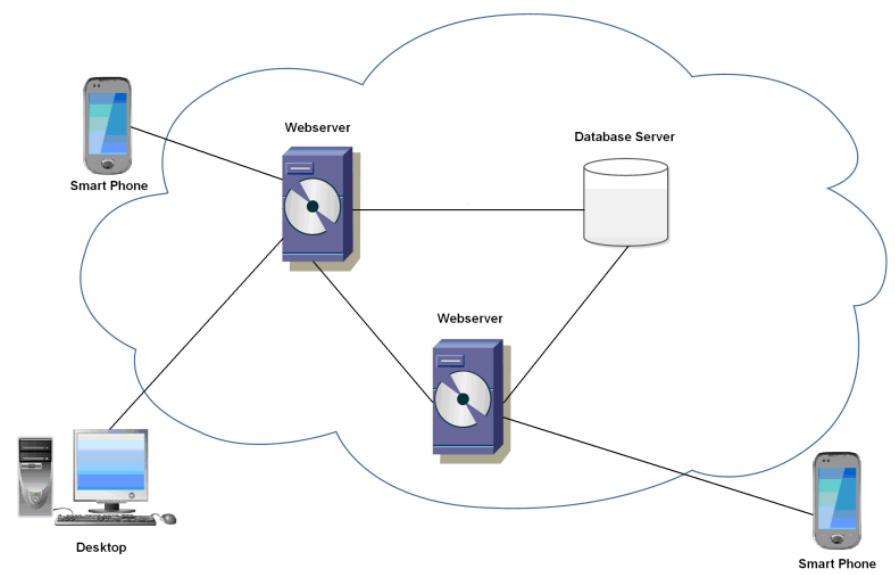

Fig. 6. The PCS front-end (the mobile interface and the application website) and the back-end (the application servers and the data storage).

Service architecture: The physical design of an individual service that encompasses all the resources used by a service. This would normally include databases, software components, legacy systems, identity stores, XML schemas and any backing stores. It is also beneficial to include any service agents employed by the service, as any change in these service agents would affect the processing capabilities of the service.
The PCS application design was divided into the front-end and back-end design as shown in figure 6 . The front-end was either an application installed on the smart phone or a website accessible from any device with a browser. On the other hand, the back-end was the server side part that manages the PCS's services and databases. The back-end is supported by ColdFusion and Amazon Machine Image (AMI) to allow the PCS to scale over the cloud to accommodate the possible increase in the number of users.

Front-end Design: In the design stage, Adobe Flash Builder has been used to simplify the integration of Adobe ColdFusion and Adobe Flex framework to create the PCS as a SWF application. ColdFusion components (CFCs) have been imported into the application and the ability to access data was done through service calls to the CFC functions. The mobile interface design was implemented using the Flash builder and the integrated MXML and FX components.

Android and IOS are both supported by Adobe Integrated Runtime environment (Adobe AIR) which can give a consistent feel for users. The functions that manipulate data on the mobile, retrieved from the web service through REST and URL requests, were coded by Actionscript integrated into Flash builder [22].

ActionScript, used in PCS implementation, is a dialect of ECMAScript (it is a superset of the syntax and semantics of the language more widely known as JavaScript), and is used primarily for the development of websites and software targeting the Adobe Flash Player platform, used on Web pages and mobile devices in the form of embedded SWF files.

The last phase was to construct the website using the flex MXML components in Flash builder which provides flexibility and scalability of running on any browser supported by Adobe Flash Player [23].

Back-end Design: Adobe ColdFusion on Cloud offers a way to easily leverage ColdFusion as a scalable service through Amazon Web Services (AWS). The ability for a Flex application to directly access data from the server is powerful because it allows for dynamic content to update the Flex application user interface without refreshing the HTML page. It is also a great advantage because it decreases number of requests to the server and the amount of content that is transferred over the network as shown in figure 7.

The AMI is available for Windows and Ubuntu operating systems. ColdFusion Windows AMI comes with the recent releases of windows operating system, configured with IIS web server (Internet Information Services) and a pre-installed MySQL database server. ColdFusion Ubuntu AMI comes with Ubuntu operating system, configured with Apache web server and a pre-installed MySQL database server. Both AMIs are available for Large and Extra-large instance types of AWS. Both AMIs have JRE built into them along with the ColdFusion Hot Fix Update.

ColdFusion is pre-installed on the Ubuntu and Windows AMIs. They can be configured using jumpstart tool. The credentials for MySQL database server were changed after installing the ColdFusion AMI [24]. 
After accessing ColdFusion AMI on AWS EC2 (Amazon Elastic Compute Cloud) instance, the instance is connected and the jumpstart tool launches and runs automatically.

Amazon provides a security mechanism to AWS instance through "security group." You can add rules to each security group that control the inbound traffic allowed to reach the instances associated with the security group. You can select and apply only those rules which are required. For Windows instances, to enable FTP-related functionality, Turned On option, have been selected in Windows Firewall and Notify me when Windows Firewall blocks a new program option has been selected as well.

By default, for ColdFusion instance set up on AWS, maximum JVM heap size is set to $512 \mathrm{MB}$. This can be configured according to our requirement based on memory available for selected instance type. For large instance, memory available is $7.5 \mathrm{~GB}$ and for extra-large instance it is $15 \mathrm{~GB}$ [25].

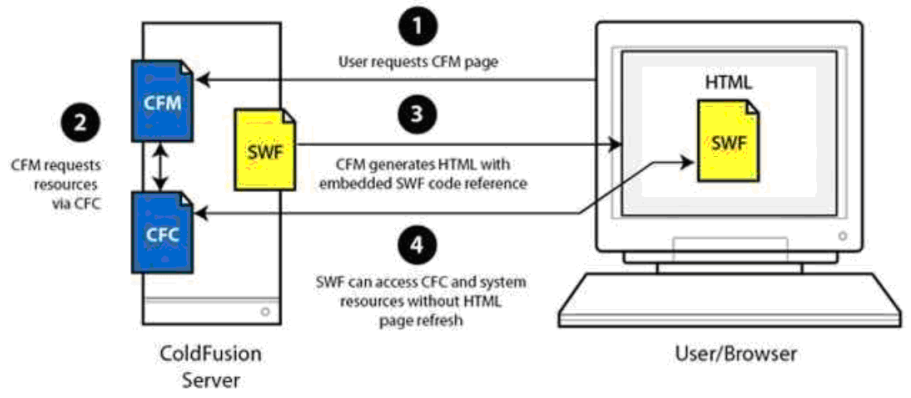

Fig. 7. The PCS front-end and back-end interaction

\section{DISCUSSION AND CONCLUSION}

M-government is the new frontier of the development agenda which needs to be prioritized by the development community at large. Developing countries should take a closer look at the potential of mobile technologies to enable better access to public information and services for the masses and adjust their current strategies, programs and processes accordingly. M-Government needs to be implemented as an integral part of e-Government. Moreover, a priority list of several high-impact m-services and a larger list need to be developed for rapid implementation by each government. The proposed system offers more collaboration between citizens and government. That system can be one of the e-government frontiers which take advantage of mobile devices to reach the majority of Egyptian citizens and improves Egypt egovernment development ranking.

The use of cloud technology in the proposed system offers reliability, sustainability as the cloud relies on government resources or public networks, so network paralysis, bandwidth bottleneck or unexpected problems could be avoided and stability of data access and sustainability of business could be achieved.

As explained in this research, e-government systems need to offer data security, as cloud technology has its security risks which need to be carefully taken into account.

\section{REFERENCES}

[1] T. Almarabeh, A. AbuAli, "A General Framework for E-Government: Definition Maturity Challenges, Opportunities, and Success", European Journal of Scientific Research, Vol. 39, No. 1, pp.: 29-42, 2010.

[2] NSN/CTO "Towards effective e-governance: The delivery of public services through local econtent, 2008, Global Summery report", http://www.cto.int/Portals/0/docs/research/towards-effectiveegovernance/ Towards-Effective-eGovernance.pdf (accessed July, 2014).

[3] Siau, K., and Y. Long, "Using Social Development Lenses to Understand E-Government Development.", Journal of Global Information Management, Vol. 14, No. 1, 2006, pp.47-62.

[4] Lallan E, "eGovernment for Development, M-Government Definitions and Models", http://www.egov4dev.org/mgovdefn.htm (accesed June, 2014)

[5] Sulaiman A. Alateyah, Richard M Crowder and Gary B Wills, "An Exploratory study of proposed factors to Adopt e-government Services" International Journal of Advanced Computer Science and Applications(IJACSA), 4(11), 2013.

[6] Johan Hellström, "Mobile phones for good governance - challenges and way forward", http://www.w3.org/2008/10/MW4D-WS/papers/ hellstrom-gov.pdf, (accessed July, 2014).

[7] NSN/CTO "Towards effective e-governance: The delivery of public services through local econtent, 2008, Global Summery report", http://www.cto.int/Portals/0/docs/research/towards-effectiveegovernance/ Towards-Effective-eGovernance.pdf (accessed July, 2014).

[8] Silvana Trimi AND Hong Sheng, "Trends in M-GOVERNMENT" , COMMUNICATIONS OF THE ACM May 2008/Vol. 51, No. 5.

[9] Nasim Qaisar and Hafiz Ghufran Ali khan, "E-Government Challenges in Public Sector:A case study of Pakistan", IJCSI International Journal of Computer Science Issues, Vol. 7, No. 5, 2010, pp. 310-317.

[10] Hiba M., Tamara A., Amer A, "E-government in Jordan", European Journal of Scientific Research, Vol. 35, No.2, 2009, pp.188-197.

[11] Johan Hellström, "Mobile phones for good governance - challenges and way forward", http://www.w3.org/2008/10/MW4D-WS/papers/ hellstrom-gov.pdf, (accessed July 2014).

[12] A. Farshid Ghyasi, "m-Government: Cases of Developing Countries", Mobile Government Lab. http://www.mgovlab.org (accessed July 12, 2014).

[13] Mohammed Alshehri and Steve Drew, "A Comprehensive Analysis of E-government services adoption in Saudi Arabia: Obstacles and Challenges " International Journal of Advanced Computer Science and Applications(IJACSA), 3(2), 2012.

[14] Raed Kanaan and Ghassan Kanaan, "The Failure of E-government in Jordan to Fulfill Potential" International Journal of Advanced Computer Science and Applications(IJACSA), 4(12), 2013.

[15] United Nations Public Administration Network, "Government survey 2012- United Nations Public Administration Programme", http://unpan1.un.org/intradoc/groups/public/documents/un/unpan048065 .pdf (accessed June 2014)

[16] Rinku Dixit "m-Government : Ruling the High - Tech Way", http://www.egovonline.net/articles/articledetails. asp?Title= m\%E2\%80\%93Government-:-Ruling-the-High-\%E2\%80\%93-TechWay\&ArticalID = 2103\&Type $=$ MCONNECT, $($ accessed July 2014)

[17] Alateyah, Sulaiman, Crowder, Richard M. and Wills, Gary B. (2013) An exploratory study of proposed factors to adopt e-government services. International Journal of Advanced Computer Science and Applications, Vol. 4, No. 11, 2013, pp. 57-66.

[18] Efraim Turban, David King, Electronic Commerce 2012: Managerial and Social Networks Perspectives, USA:Pearson, 2012.

[19] David Villegas, Norman Bobroff, Ivan Rodero, Javier Delgado, Yanbin Liu, Aditya Devarakonda, Liana Fong, S. Masoud Sadjadi, Manish Parashar, "Cloud federation in a layered service model," Journal of Computer and System Sciences, Vol. 78, Issue 5, September 2012, pp. $1330-1344$ 
[20] Wei Liu, Feiyan Shi,Wei Du and Hongfeng Li "A Cost-Aware Resource Selection for Data intensive Applications in Cloud-oriented Data Centers" in the International Journal of Information Technology and Computer Science 2011.

[21] Perera, S.; Kumarasiri, R.; Kamburugamuva, S.; Fernando, S.; Weerawarana, S.; Fremantle, P., "Cloud Services Gateway: A Tool for Exposing Private Services to the Public Cloud with Fine-grained Control," Parallel and Distributed Processing Symposium Workshops \& PhD Forum (IPDPSW), 2012 IEEE 26th International, 2012 , pp.: 2237 2246.

[22] Costanzo, A. ; Faro, A. ; Giordano, D. ; Spampinato, C., "Context aware services for mobile users: JQMobile vs Flash Builder implementations," Computer Science and Information Systems (FedCSIS), 2012 Federated Conference on, pp.: 1185 - 1192, 2012.
[23] Rainer, B. ; Lederer, S. ; Muller, C. ; Timmerer, C., "A seamless Web integration of adaptive HTTP streaming," Signal Processing Conference (EUSIPCO), 2012 Proceedings of the 20th European, pp.: 1519 - 1523, 2012.

[24] Design and Implementation of Coldfusion-Based Web Application Firewall Feng Fangmei ; Changgeng Shao ; Dan Liu Computer Science \& Service System (CSSS), 2012 International Conference on, pp.: 659 $662,2012$.

[25] von Laszewski, G., Diaz, J., Fugang Wang, Fox, G.C., "Comparison of Multiple Cloud Frameworks," Cloud Computing (CLOUD), 2012 IEEE 5th International Conference on Communication, Networking \& Broadcasting ; Components, Circuits, Devices \& Systems ; Computing \& Processing Hardware/Software, 2012 , pp.: 734 - 741. 